\title{
Volcanic and Solar Forcing of the Tropical Pacific Over the Past 1000 Years
}

\author{
Michael E. Mann ${ }^{1}$, Mark A. Cane ${ }^{2}$, Stephen E. Zebiak ${ }^{3}$ \& Amy Clement ${ }^{4}$ \\ 1 Department of Environmental Sciences, University of Virginia, Clark Hall, Charlottesville, Virginia, \\ 22903, USA; mann@virginia.edu \\ 2 Lamont Doherty Earth Observatory, Columbia University, Palisades, New York, 10964, USA \\ 3 International Research Institute for Climate Prediction, Palisades, New York, 10964, USA \\ 4 Rosenstiel School of Marine and Atmospheric Science, University of Miami, Miami, Florida, 33149, \\ USA
}

Journal of Climate, in press 


\begin{abstract}
We investigate the response of El Niño to natural radiative forcing changes over the past 1000 years based on numerical experiments employing the Zebiak-Cane (Zebiak and Cane, 1987) model of the tropical Pacific coupled ocean-atmosphere system. Previously published empirical results (Adams et al, 2003) demonstrating a statistically significant tendency towards El Niño conditions in response to past volcanic radiative forcing are reproduced in the model experiments. A combination of responses to past changes in volcanic and solar radiative forcing closely reproduces changes in the mean state and interannual variability in El Niño in past centuries recorded from fossil corals. Our experiments suggest that the dynamics of El Niño may have played an important role in the response of the global climate to past changes in radiative forcing.
\end{abstract}

\title{
1. Introduction
}

The El Niño-Southern Oscillation (ENSO) is associated with a quasi-periodic (3-7 year timescale) warming (El Niño) and cooling (La Niña) of the eastern and central tropical Pacific Ocean surface that influences global-scale climate. Bjerknes (1969) identified the fundamental ocean-atmospheric feedbacks (the "Bjerknes Feedbacks") at the core of this instability in the tropical ocean-atmosphere system, and a body of work in past decades has elucidated the factors underlying its natural interannual oscillatory behavior. Only more recently has the role of ENSO in anthropogenic climate change (Meehl and Washington, 1996; Trenberth and Hoar, 1997; Rajagopalan et al., 1997; Cane et al., 1997; Knutson et al., 1997; Noda et al., 1999; Timmermann et al, 1999; Collins, 2000ab; Boer et al., 2000; Meehl et al., 2000), or longer-term natural climate changes (Clement et al., 2000; Liu et al., 2000) been investigated. 
Previous studies employing the simplified Zebiak-Cane (henceforth "ZC") model of the tropical Pacific coupled ocean-atmosphere system (Zebiak and Cane, 1987), have been used to investigate the potential response of ENSO to anomalous radiative forcing, including that associated with anthropogenic greenhouse gas concentration increases (Clement et al., 1996, Cane et al, 1997). Those studies described an "ocean thermostat" mechanism in which a heating of the tropical Pacific leads to a cooling of the eastern part of the basin. This result arises from the different surface temperature response in the eastern and western Pacific: In the west, where the thermocline is deep, the response to a surface heating is largely thermodynamic and the mixed layer adjusts with an increased temperature. In the east where the thermocline is shallow, cooling by vertical advection offsets the surface heating producing a smaller temperature response. The increased zonal SST gradient accelerates the trade winds, which leads to further thermocline shoaling and cooling by vertical advection in the east, further accelerating the winds. This 'climatological' Bjerknes feedback, akin to that which operates on interannual timescales, leads to a cooling of the eastern equatorial Pacific in response to a heating of the basin. Clement et al. (1996) and Cane et al. (1997) referred to this response as "La Niña-like" since there is a cooling in the east, as during a La Niña event, but there is also a warming in the west, which does not generally occur during a La Niña. Further, such a response is "La Niña-like" (and the reverse pattern of response to a cooling of the basin is "El Niño-like") in that it resembles the characteristic ENSO pattern, but rather than being associated with a distinct ENSO event, it is associated with a shift in both mean state and variability towards such conditions on a multi-year or even multidecadal timescale. In this paper, we will thus use the terminology "El Niño-like" to mean a warmer eastern equatorial Pacific and increased ENSO variability, and "La Niña-like" to mean a cooler eastern equatorial Pacific and decreased variability 
The feedbacks governing the above response are often not well-represented in coarser resolution global coupled models (Latif et al, 2001). The response of the zonal gradient in the tropical Pacific of such models to heating of the surface by higher levels of greenhouse gases is quite model-dependent (Collins, 2000b), possibly due to the behavior of certain feedbacks in the models (e.g. cloud radiative feedbacks) that respond differently in different models, and are admittedly absent in the ZC model.

Here we investigate the response of ENSO to estimated changes in natural radiative forcing associated with explosive volcanic and solar radiative forcing changes over the past 1000 years. Several new and distinct insights from the paleoclimate record of the past few centuries guide these investigations: (i) An analysis of reconstructed sea surface temperature (SST) patterns over the past few centuries (Waple et al., 2002) indicates greater warming in the western Pacific warm pool than in the central or eastern tropical Pacific in association with estimated past increases in solar irradiance, reminiscent of a La Niña-like anomaly in response to increased solar irradiance. (ii) An empirical analysis of proxy-based reconstructions over the past 3 centuries (Adams et al., 2003) finds statistical evidence for a tendency for El Niño conditions during the first few years following explosive tropical volcanic eruptions (with a tendency for a subsequent rebound into La Niña conditions). This evidence seems to substantiate previous claims of a relationship between tropical volcanic eruptions and El Niño events based on the relatively short instrumental record (Handler, 1984) though such claims are controversial (e.g. Nicholls, 1990; Robock, 2000). (iii) Century-scale changes in the state of ENSO appear to have varied oppositely with those in hemispheric or global mean temperature over the past millennium. Cobb et al (2003) provide evidence (in terms of both mean state and interannual variability) for an El Niño-like state during the otherwise generally cold 17th century (e.g. Crowley, 2000; Mann et al, 2003) and a La Niña-like state during the otherwise relatively mild 
12th/13th centuries (Crowley, 2000; Mann et al, 2003). Hendy et al (2002), similarly, find evidence for a relative absence of cooling in the tropical Pacific during the otherwise cold late 16th-19th centuries, while Jones et al (2001) show evidence for a shift to an El Niño-like mean state during the late 17 th century/early 18 th century. Verschuren et al (2000) provide lake-level evidence in equatorial east Africa (Kenya) for peak wet conditions during the mid-17th to the mid-18th centuries, and dry conditions during the early (11th-13th) centuries of the millennium, reminiscent of anomalies typically associated with El Niño and La Niña conditions, respectively. A similar pattern of drought in earlier centuries and wet conditions in later centuries in the desert southwest of North America (Woodhouse and Overpeck, 1998) favors this interpretation as well.

Each of the above observations seems to suggest a relationship that is consistent with the thermostat mechanism of Clement et al. (1996) whereby the temperature of the eastern equatorial Pacific varies negatively with changes in radiative forcing as discussed earlier. In this study, we

propose an internally-consistent framework, that is, the influence of the "thermostat" mechanism of Clement et al (1996) active in the ZC model, for explaining each of these observations, employing experiments with a relatively simple model of the coupled tropical Pacific oceanatmosphere system forced by estimated changes in past natural radiative forcing.

\section{Methods}

Experiments are performed with the ZC model of the tropical coupled Pacific ocean-atmosphere system (Zebiak and Cane, 1987). While global coupled ocean-atmosphere models are capable of simulating ENSO (albeit with some shortcomings- Latif et al. 2001), such models are too computationally expensive to perform many 1000 year long integrations. Isolation of the signals of interest in this study requires, as discussed below, ensembles of multiple realizations of 
millennial forcing scenarios. Moreover, in a global coupled model tropical and extratropical processes and coupling between them must be considered in analyzing the response of the model to a particular forcing scenario. By contrast any response that is observed in our experiments employing the ZC model must, by design, arise from intrinsic tropical Pacific climate mechanisms.

Naturally, there are other potentially important potential responses associated with cloud radiative feedbacks, or large-scale monsoonal responses, or extratropical feedbacks on the tropics, that are not included in the ZC model. However, that our model results are in agreement with data, as shown below, suggests that the essence of the response, the dynamical thermostat of Clement et al (1996), is a potentially important mechanism operating in nature. This mechanism is observed in at least one global coupled ocean-atmosphere model (Otto Bliesner et al., 2003). It is possible that we are getting the right answer for the wrong reason, or an incomplete answer, and that the observed changes are due to processes absent in the ZC model. Similar experiments carried out with global coupled ocean-atmosphere models would provide additional insights to those offered by our analysis.

It should be noted that changes in mean state cannot be separated from changes in interannual variability in these experiments. Intervals of increased variability (increased frequency and amplitude of individual interannual events) are associated with a mean warming of the eastern equatorial Pacific in the ZC model (though not in all coupled models--e.g. Arblaster et al, 2003). This is due to the skewness of the variability about the base (zero anomaly) state in the model, with El Niño events typically characterized by large positive departures, and La Niña events somewhat weaker negative departures. As Niño3 warming associated with an El Niño event is greater than the cooling associated with a La Niña event, increases in the amplitude of 
interannual variability are associated with a more "El Niño" like mean state in the ZC model, while decreases in the amplitude of interannual variability are associated with a more "La Niña" like mean state. It should also be noted that the response of ENSO dynamics in the ZC model to radiative forcing is not linear. Clement et al (1996) show that there is high sensitivity for small forcing, and lower sensitivity for large forcing. The non-linearity of the response also means that the response to combined (e.g. solar+volcanic) radiative forcing is not simply the sum of the two responses.

Model Experimental Design. Consistent with the ZC model formulation, the radiative forcing is imposed as an anomalous surface heat flux into the ocean mixed layer. We performed separate experiments employing (a) volcanic only forcing, (b) solar forcing only, and (c) combined (solar + volcanic) natural forcing, over the interval AD 1000-1999. To isolate the signal of the model's forced response from the considerable internal variability of the ZC model, we calculate mean responses from an ensemble of realizations of the response of the model to the different 1000 year forcing scenarios. The initial conditions of each realization differ; each is started using different random conditions from a control simulation with fixed (AD 1000-1999 mean) radiative forcing. We employ Crowley's (2000) solar and volcanic radiative forcing estimates over the past 1000 years, with some minor modifications. Since Crowley (2000) provides radiative forcing estimates representative of the hemispheric mean, we scale the estimates by a factor of 1.57 to yield an estimate of the associated equatorial radiative forcing required by the ZC model. This scaling assumes a cosine latitudinal dependence of top-of-the-atmosphere radiative forcing anomalies associated with uniform changes in solar constant or optical depth. We ignore the slight latitudinal dependence of the forcing within the tropical domain $\left(30^{\circ} \mathrm{S}\right.$ to $30^{\circ} \mathrm{N}$ ) of the $\mathrm{ZC}$ model. For simplicity, all volcanic eruptions are assumed to occur during the January of the eruption year and responses are examined on a calendar (Jan-Dec) annual mean basis. All imposed radiative forcings are assumed uniform within the year, prescribed on an 
annual basis. Additional experiments demonstrate essentially identical results (i) if the volcanic forcing is instead prescribed on a monthly basis (through fitting of a smooth exponential decay to the annual mean radiative forcing estimates associated with each individual event), (ii) whether eruptions are assumed to occur during the boreal summer or winter and (iii) whether the mean response is diagnosed based on a traditional calendar (Jan-Dec) or boreal winter centered (JunMay) annual mean basis.

As a diagnostic of the model's ENSO behavior, we evaluate the Niño3 index of model SST anomalies in the eastern tropical Pacific region closely associated with El Niño and La Niña events $\left(90-150^{\circ} \mathrm{W}\right.$ and $\left.5^{\circ} \mathrm{S}-5^{\circ} \mathrm{N}\right)$. We adopt the convention that the "year" date is defined by the January of the winter during which an El Niño event occurs.

Radiative Forcing Estimates. The hemispheric volcanic radiative forcing of Crowley (2000) is based on contributions from both extratropical and tropical explosive eruptions. However, the relevant forcings are the ones that can provide a tropical volcanic dust veil over the tropical Pacific domain of interest. This forcing is provided by eruptions occurring within the tropical band $30^{\circ} \mathrm{S}$ to $30^{\circ} \mathrm{N}$. . It should be noted that Adams et al (2003) for this same reason, considered only tropical eruptions in examining the empirical evidence for the response of ENSO to past volcanic forcing. We thus remove from Crowley's (2000) volcanic radiative forcing series all events that have not been confirmed, based on available historical or geological information (Simpkin and Siebert, 1994), or bipolar ice core volcanic aerosol deposit evidence (Crowley, 2000), as being of tropical origin. The timing of certain eruptions has been shifted by one or two years based on a recent reevaluation of the volcanic forcing chronologies ( $\mathrm{T}$. Crowley, personal communication). Solar radiative forcing histories are somewhat uncertain, and a number of different reconstructions of solar irradiance have been produced in recent years (Crowley, 2000; 
Lean et al, 1995; 2002), highlighting the uncertainty that still exists in the history of this forcing. We have used the solar irradiance reconstruction of Crowley (2000) based on a splice of the Lean et al (1995) estimate with $\mathrm{Be}^{10}$ cosmogenic isotope evidence back to $\mathrm{AD} 1000$, smoothing the resulting series with a 40 year low pass filter to insure homogenous frequency-domain fidelity to the imposed forcing over time. The reconstruction is in the lower range of existing solar irradiance reconstructions, roughly 40\% smaller in amplitude than Lean et al (1995), smaller than several other reconstructions considered by Crowley (2000), and far smaller than the very large solar forcing recently used by Gonzalez-Rouco et al (2003). However, the amplitude is about twice as large as alternative reconstructions based purely on the amplitude of the 11 year solar cycle (Lean et al, 2002). We have thus chosen what we consider a "mid range" estimate of this uncertain long-term forcing. Modestly different results would be obtained if other solar forcing histories were used.

We do not consider in this study the potential impact of modern (19th and 20th century) anthropogenic forcing. While Cane et al (1997) examined the possible influence of anthropogenic greenhouse gas concentration changes on 20th century ENSO trends, the magnitude and spatial pattern of total anthropogenic radiative forcing due to the combined effects of greenhouse gas and aerosol radiative forcing is not yet well constrained (Ramaswamy et al, 2001). Certain impacts, such as production of aerosol from biomass burning in Indonesia, for example, may represent a significant, yet difficult to estimate radiative forcing over parts of the Indo-Pacific domain (Hauglustaine et al., 1999). Furthermore, the complicating impact of extratropical feedbacks associated with the subduction of extratratropical water masses may be more significant in a non-stationary scenario of steadily increasing forcing, suggesting the greater possibility of potentially offsetting extratropical feedbacks in such a scenario. We defer any discussion of potential anthropogenic impacts to future investigation. 


\section{Results}

In Figure 1, we show the ensemble mean Niño3 response of the model to tropical volcanic and solar radiative forcing over the past 1000 years. For an ensemble of 100 realizations of the response to the 1000 year volcanic forcing scenario, an El Niño-like response (and weaker subsequent La Niña-El Niño cycling) is clearly observed in response to each tropical volcanic forcing event. For more modest ensembles ( 5 and 20 realizations, taken from the first 5 and first 20 , respectively, of the 100 realization ensemble), the response to the weaker volcanic forcing events is largely lost in the noise of the ZC model internal variability. However, the response to the greater magnitude eruptions (especially the AD 1259 eruption and the eruptions of the early 19th century) are evident even in the most modest (5 realization) ensemble. In fact, the responses to the largest eruptions are typically evident in individual realizations, consistent with the proposition that the signal should be detectable in the unique realization that the earth's climate has actually experienced over the past 1000 years.

The ensemble-mean Niño3 response to volcanic forcing, which consists of individual impulsive forcings, is modest, averaging roughly to a $0.2^{\circ} \mathrm{C}$ anomaly per $-1 \mathrm{~W} / \mathrm{m}^{2}$ forcing (it should be noted that the response of the model to radiative forcing is not linear in the radiative forcing--see e.g. Clement et al, 1996). Interestingly, while the solar irradiance forcing is roughly an order of magnitude smaller than the volcanic forcing in its peak amplitude, the lower-frequency nature of the associated forcing (which is long compared to the interannual timescales characterizing El Niño events) allows a more equilibrated response to the forcing. On 40 year and longer timescales, the ensemble-mean Niño3 and solar forcing time series are strongly negatively correlated $(r=-0.77$, significant at the $p=0.001$ level taking into account serial correlation) with 
the response lagging the forcing by 5-20 years (average of 14 years), which is likely due to ocean adjustment processes in the model. The typical ensemble-mean Niño3 response on the centennial timescale is approximately $0.5^{\circ} \mathrm{C}$ per $-1 \mathrm{~W} / \mathrm{m}^{2}$ (compare the right and left scales of variation in Figure 1c). Thus, while solar forcing is considerably weaker in peak amplitude to the volcanic forcing, the lower-frequency nature of the forcing appears to allow a substantially larger relative Niño3 response.

In Figure 2, we show the results of a "Superposed Epoch Analysis" ("SEA"), similar to that used by used by Adams et al (2003) to identify the Niño3 response to tropical volcanic radiative forcing based on proxy-reconstruction of volcanic forcing and ENSO indices back through the mid 17th century. The SEA approach (see e.g. Panofsky and Brier, 1965; Bradley et al, 1987; Sear et al, 1987; Mass and Portman, 1989) composites anomalies by their lead/lag relative to the timing of explosive volcanic eruption events to establish whether or not a statistically significant response to volcanic forcing is evident in some list of events. These analyses demonstrate the composite behavior preceding, coinciding with, and following tropical volcanic eruptions. Fig $2 \mathrm{a}$ show the results using moderate eruptions (radiative forcing exceeding $-2 \mathrm{~W} / \mathrm{m}^{2}$ ) between AD 1649 and 1868, the pre-instrumental period considered by Adams et al (2003) which includes 7 eruptions (AD 1674, 1681, 1695, 1809, 1815, 1831, 1835). In Fig 2b we show the results based on the 7 largest eruptions (radiative forcing exceeding $-4 \mathrm{~W} / \mathrm{m}^{2}$ ) over the full AD 1000-1999 period (the eruptions were in $\mathrm{AD} 1259,1453,1601,1641,1809,1815$, and 1831). We determined (positive and negative) 95\% confidence levels for the post-eruption anomalies from the distribution of the pre-eruption composites. For both eruption lists, the results are highly reminiscent of the empirical results of Adams et al (2003), showing a significant multi-year ENSO response. The response is characterized by a tendency for El Niño conditions to emerge in the year of the eruption, weaken, and exhibit damped subsequent oscillations between La Niña 
and El Niño conditions in subsequent years. Based on the 100 realizations, the probability of an El Niño event (Niño3 anomaly $>1{ }^{\circ} \mathrm{C}$ ) occurring in the year following a larger eruption (as in Fig 2b) is 63\%; for the eruptions between 1649 and 1868 (Fig 2a) it is 55\%. For comparison, the probability over all years is $33 \%$. The approximate doubling of the probability of a warm event in the year following the eruption is similar to that observed by Adams et al (2003).

It should be stressed that these results suggest a statistical, rather than deterministic, relationship between volcanic forcing and ENSO-like response. As discussed earlier (e.g. in the context of the discussion of Figure 1b), in any one single realization of the actual climate, there is a sizable probability that an El Niño event will not occur. Only for the largest amplitude forcing events (e.g. AD 1259) is an El Niño-like response expected to be observed in almost any independent realization of the climate based on our experiments. For the relatively modest amplitude volcanic eruptions of the 20th century (which contrast with numerous larger eruptions in prior centuries), it is difficult to relate the observed actual sequence of El Niño events to explosive volcanism (see Nicholls 1990, Robock, 2000, Adams et al, 2003). Indeed, the fact that most El Niño events during the late 19th and 20th century appear to be predictable more than a year in advance without including the effects of volcanic forcing (Chen et al, 2004) speaks to the likelihood that internal variability, rather than explosive volcanism, dominates the observed recent history of ENSO. The similarity in timing between certain notable recent El Niño events and large tropical forcing events (e.g. the 1982 El Chichón eruption and the 1991 Pinatubo eruption) may in fact be entirely coincidental. Our results, as the empirical results of Adams et al (2003), suggest, however, that some changes in the statistical attributes of ENSO are in fact likely to be related to changes in explosive volcanic forcing over multidecadal or longer intervals. 
In Figure 3, we show the Niño3 response (100 realization ensemble mean) for the combined solar +volcanic forcing from AD 1000-1999. Peak-to-peak variations on multidecadal and century timescales (Figure $3 \mathrm{~b}$ ) range from $0.2^{\circ}$ to $0.4^{\circ} \mathrm{C}$, indicating climatically significant longterm change in ENSO mean state. Also shown is a history of ENSO inferred from oxygen isotopes in fossil corals. The corals, collected at Palmyra in the tropical central Pacific, are from intermittent time periods over the past millennium (viz. Fig. 3). The corals are interpreted as indicating warm-event (cold-event) conditions for negative (positive) isotopic departures, based on extrapolation from recent conditions (Cobb et al, 2003). ENSO-related salinity and temperature influences in the region of Palmyra (which are currently associated with wet and warm conditions during a warm-event), have a mutually reinforcing influence on oxygen isotopic fractionation (negative isotopic departures during warm-events). An important caveat in this regard is that Palmyra lies at the fringe of the cold-tongue region of the eastern tropical Pacific, a region where the relationship between SST changes and patterns of convection/precipitation might have changed as the mean climate changed. If so, then the quantitative relationship between isotopic departure and indices of ENSO such as the Niño3 index, may not be stationary over time. It is unlikely, however, that the sign of the relationship between ENSO indicators and isotopic departures, would have changed back in time.

The coral data have been standardized to have the same mean and annual standard deviation as the composite Niño3 series when averaged over all 3 overlapping segments. The means and standard deviations of the individual segments are allowed to vary. This imposes an implicit amplitude scale on the Niño3 history inferred from the isotope data. If, instead, the isotope data are scaled based on the relationship between the 20th century coral segment (not shown) and the overlapping instrumental Niño3 record, the inferred changes in Niño3 are approximately twice as 
large. As discussed above, however, it is not clear that such a 20th century scaling will precisely hold back in time.

As the coral reconstruction provides only one realization of the history of ENSO in past centuries, it would be quite surprising if the ensemble mean response of even a perfect model would match the observations exactly, especially at the seasonal to interannual timescale where intrinsic ENSO variability dominates, and where dating uncertainties in the coral records make precise comparisons perilous. However, the agreement between predicted and observed lowfrequency changes in mean state, which should be more robust based on statistical sampling considerations, is notable: cold late 12th/early13th century central/eastern tropical Pacific SSTs, moderate 14th/early 15th century central/eastern tropical Pacific SSTs, and warm late 17th century central/eastern tropical Pacific SSTs occur in both model and observations. For each of the three available segments the means of the observations and the model ensemble are consistent within the sampling distribution from the ensemble. Moreover, the late 17th century and late 12 th/early 13 th century means are nearly statistically distinct in the model simulations (the inter-fourth quartile range for the mean of the latter period lies entirely above the ensemble average mean of the earlier period, indicating that the mean of the later period would be expected to be higher than that of the earlier period in roughly 7 out of every 8 realizations). Given the model prediction, we can therefore conclude that the later period would be likely to have a greater mean than the earlier period in the one observed realization (i.e., that provided by the coral data) with a roughly $90 \%$ probability. A close similarity is also found in the changes in the amplitude of interannual variability between different time intervals. The numerous large El Niño events of the late 17th century and the lack of large El Niño events in the late 12th/early 13th century are similar for both model and observations; in the model, this difference is associated primarily with an abundance and absence, respectively, of large volcanic forcing 
events at those times. The increase in standard deviation in the 17 th century interval relative to the 12 th/13th century interval is statistically significant for both the coral observations and the model simulations (observations: 0.19 vs. 0.15 , model: 0.21 vs. $0.16 ; p<0.1$ for the difference in both cases). A comparison with the low-frequency changes in Niño3 due to volcanic forcing only (Figure 3c) indicates that many of the low-frequency changes in mean and variability arise from volcanic forcing alone, with solar forcing generally playing a secondary role. Thus, the results shown are likely to be qualitatively correct even in the face of relatively large uncertainties in the amplitude of solar radiative forcing in past centuries.

A caveat that should be noted in the comparisons with the coral records is that if the alternative scaling discussed above is used (based on the statistical relationship between the model coral data and instrumental record during the 20th century), the differences in means between the different coral segments are roughly twice as large, and the differences between the 12th/13th and 17 th century intervals fall moderately outside the interfourth quartile range of the model simulations. There are at least 4 possible reasons for this discrepancy: (1) the model is underestimating the true response of the system to natural radiative forcing changes, (2) the true natural radiative forcing over the tropical Pacific in past centuries is greater than assumed in the radiative forcing estimates used, (3) the actual climate history is, in part, the result of a relatively unusual realization of the internal variability, or (4) long-term changes in mean state have changed the precise relationship between ENSO precipitation and temperature changes in the Palmyra region, and thus, the quantitative interpretation of the isotope departures in terms of e.g. Niño3 temperatures. It is difficult to determine, at present, which of these explanations is most viable. As additional fossil coral evidence is recovered from the tropical central Pacific for other time periods, it should be possible to further examine the relationship between natural radiative forcing and past changes in the tropical Pacific. Observations from the mid 13th century 
following the very large AD 1259 eruption, or during the early 19th century period of relatively intense tropical explosive volcanic activity should, given our simulations, indicate a pronounced tendency towards an El Niño state. Anthropogenic impacts, which are increasingly important subsequent to the mid 19th century, are not considered in this study. Cane et al (1997) suggest the possibility of a cooling central/eastern equatorial Pacific in response to downward longwave forcing by increasing greenhouse gas concentrations, consistent with the mechanisms discussed in this study. However, we caution the reader that the response to anthropogenic radiative forcing may, as discussed earlier, may be more complicated than that associated with the natural radiative forcing changes considered in this study.

\section{Conclusions}

Our model experiments reproduce the empirical observations of a short-term ENSO response to explosive tropical eruptions, as well as the tendency for an El Niño-like state in the tropical Pacific during the so-called "Little Ice Age" and a La Niña-like state during the "Medieval Warm Period.”. In the modern climate, moderate El Niño conditions are associated with a relative warming on the order of tenths of a degree $\left({ }^{\circ} \mathrm{C}\right)$ in global mean temperatures. Moreover, such conditions are associated with a pattern of widespread tropical warming but weaker warming or even cooling in some regions of the extratropics (Seager et al, 2003). The response of the tropical Pacific to radiative forcing isolated in this study thus implies both a decrease in the amplitude of the global or hemispheric-mean warming (cooling) associated with increased (decreased) radiative forcing in past centuries, and a decrease (increase) in the poleward temperature gradient between equator and midlatitudes in response to increased (decreased) radiative forcing. Such a response would argue for somewhat lower amplitude variability in actual hemispheric or global mean temperature in past centuries than is predicted by models 
which either do no resolve at all, or resolve incompletely, the physics underlying ENSO (e.g. Rind et al, 1999; Crowley, 2000; Gonzalez-Rouco et al, 2003). This response would furthermore help to explain apparent evidence that extratropical temperature changes in past centuries (e.g. Esper et al, 2002) have been greater in amplitude than tropical (Hendy et al, 2002) or full hemispheric-scale (e.g. Mann et al, 2003) temperature changes. Future experiments using higher resolution global coupled ocean-atmosphere models should provide further insights into the response of the tropical Pacific to past radiative forcing changes.

\section{Acknowledgements}

We thank Dr. Tom Crowley for help in revising the volcanic forcing series used in the study. This research was supported (M.E.M.) by the NOAA- and NSF-supported "Earth Systems History" program and the NSF Paleoclimate program (A.C., grant \#ATM-0134742).

\section{References}

Adams, J.B., M.E. Mann, and C.M. Ammann, 2003: Proxy evidence for an El Nino-like Response to Volcanic Forcing, Nature, 426, 274-278.

Arblaster, J.M., G.A. Meehl and A. Moore, 2002: Interdecadal modulation of Australian rainfall. Clim. Dyn., 18, 519-531.

Boer, J.G., G. Flato, M.C. Reader, and D.A. Ramsden, 2000: A transient climate change simulation with greenhouse gas and aerosol forcing: experimental design and comparison with the instrumental record for the 20th century, Clim. Dyn. 16, 405-425.

Bjerknes, J. Atmospheric teleconnections from the equatorial Pacific, Mon. Weath. Rev. 97, 163172 (1969).

Bradley, R.S., Diaz, H.F., Kiladis, G.N., and Eischeid, J.K, 1987: ENSO signal in continental temperature and precipitation records, Nature 327, 497-501. 
Cane, M.A., A.C. Clement, A. Kaplan, Y. Kushnir, D. Pozdnyakov, R. Seager, S.E. Zebiak, and R. Murtugudde, 1997: Twentieth-century sea surface temperature trends, Science 275, 957-960.

Chen, D., Cane, M.A., Kaplan, A., Zebiak, S.E., Huang, D., 2004: Predictability of El Nino over the past 148 years, 428, Nature, 733-736.

Clement, A.C., R. Seager, and M.A. Cane, 2000: Suppression of El Nino during the midHolocene by changes in the Earth's orbit, Paleoceanography, 15, 731-737.

Clement, A.C., R. Seager, M.A. Cane, and S.E. Zebiak, 1996: An ocean dynamical thermostat, J. Clim. 9, 2190-2196.

Cobb, K.M., C.D. Charles, H. Cheng, and R.L Edwards, 2003: El Niño-Southern Oscillation and tropical Pacific climate during the last millennium, Nature, 424, 271-276.

Collins, M., 2000a: The El Niño-Southern Oscillation in the Second Hadley Centre Coupled Model and Its Response to Greenhouse Warming. Journal of Climate, 13, 1299-1312.

Collins, M., 2000b: Understanding uncertainties in the response of ENSO to greenhouse warming, Geophys. Res. Lett., 27 (21), 3509, doi: 10.1029/2000GL011747.

Crowley, T.J., 2000: Causes of Climate Change Over the Past 1000 years, Science 289, 270-277.

Esper, J., E.R. Cook, and F.H. Schweingruber, 2002: Low-Frequency Signals in Long Tree-Ring Chronologies for Reconstructing Past Temperature Variability, Science, 295, 2250-2253.

Gonzalez-Rouco, F., H. von Storch, and E. Zorita, 2003: Deep soil temperature as proxy for surface air-temperature in a coupled model simulation of the last thousand years, Geophys. Res. Lett., 30(21), 2116, doi:10.1029/2003GL018264.

Handler, P., 1984: Possible association of stratospheric aerosols and El Niño type events, Geophys. Res. Lett., 11, 1121-1124. 
Hauglustaine, D.A., G.P. Brasseur, and J.S. Levine, 1999: A sensitivity simulation of tropospheric ozone changes due to the 1997 Indonesian fire emissions. Geophys. Res. Lett, 26, 3305-3308.

Hendy, E.J., M.K. Gagan, C.A. Alibert, M.T. McCullock, J.M. Lough, and O.J. Isdale, 2002: Abrupt Decrease in Tropical Pacific Sea Surface Salinity at End of Little Ice Age, Science 295, 1511-1514.

Jones, P.D., T.J. Osborn, and K.R. Briffa, 2001: The Evolution of Climate over the Last Millenium, Science, 292, 662-667.

Knutson, T., S. Manabe, and D. Gu, 1997: Simulated ENSO in a global coupled oceanatmosphere model: Multidecadal amplitude modulation and $\mathrm{CO}_{2}$ sensitivity, J. Clim. 10, 138-161.

Latif, M. et al, 2001: ENSIP: the El Nino simulation intercomparison project. Clim. Dyn., 18, 255-276.

Lean, J., J. Beer, and R.S. Bradley, 1995: Reconstruction of Solar Irradiance Since 1610: Implications for Climate Change, Geophys. Res. Lett., 22, 3195-3198,. 22, 3195-3198.

Lean, J.L., Y.-M. Wang, and N.R. Sheeley, Jr., 2002: The effect of increasing solar activity on the Sun's total and open magnetic flux during multiple cycles: Implications for solar forcing of climate, Geophys. Res. Lett., 29, 224, doi:10.1029/2002GL015880.

Liu, Z., J. Kutzbach, and L. Wu, 2000: Modeling Climate Shift of El Nino Variability in the Holocene, Geophys. Res. Lett., 27, 2265-2268.

Mann, M.E., C.M. Ammann, R.S. Bradley, K.R. Briffa, T.J. Crowley, M.K. Hughes, P.D. Jones, M. Oppenheimer, T.J. Osborn, J.T. Overpeck, S. Rutherford, K.E. Trenberth, T.M.L. Wigley, 2003: On Past Temperatures and Anomalous Late 20th Century Warmth, Eos, $84,256-258$. 
Mass, C. F. and D. A. Portman, 1989: Major volcanic eruptions and climate: A critical evaluation. J. Climate 2, 566-593.

Meehl, G.A. and W.M. Washington, 1996: El Niño-like climate change in a model with increased atmospheric $\mathrm{CO}_{2}$ concentrations, Nature 382, 56-60.

Meehl, G.A., W.D. Collins, B. Boville, J.T. Kiehl, T.M.L. Wigley, and J.M. Arblaster, 2000: Response of the NCAR Climate System Model to increased $\mathrm{CO}_{2}$ and the role of physical processes, J. Clim. 13, 1879-1898.

Nicholls, N., 1990: Low-latitude volcanic eruptions and the El Niño/Southern Oscillation: A Reply, Int. J. Climatol. 10, 425-429.

Noda, A., K. Yamaguchi, S. Yamaki, and S. Yukimoto, 1999: Relationship between natural variability and $\mathrm{CO} 2$-induced warming pattern: MRI AOGCM experiment, Paper presented at the 10th Symposium on Global Change Studies, Dallas, Texas, 10-15 January 1999, American Meteorological Society.

Otto-Bliesner, B.L., E.C. Brady, S-I Shin, Z. Liu, and C. Shields, 2003: Modeling El Nino and its tropical teleconnections during the last glacial-interglacial cycle, Geophys. Res. Lett., 30, 2198, doi: 10.1029/2003GL018553.

Panofsky, H.A. and G.W. Brier, 1965: Some Applications of Statistics to Meteorology, Penn. State University, University Park, Pennsylvania.

Rajagopalan, B., U. Lall, and M.A. Cane, 1997: Anomalous ENSO Occurrences: An Alternate View, J. Clim., 10, 3251-2357.

Ramaswamy, V. et al.,"Radiative Forcing of Climate Change", Chapter 6 in Climate Change 2001, The Scientific Basis, Working Group I to the Third Assessment Report of the Intergovernmental Panel on Climate Change (IPCC), Cambridge University Press 2001, pp. 349-416. 
Rind, D., J. Lean, and R. Healy, Simulated time-dependent climate response to solar radiative forcing since 1600, Journal of Geophysical Research, 104 (January 27, no. D2), 19731990, 1999.

Robock, A., 2000: Volcanic eruptions and climate, Rev. Geophys., 38, 191-219.

Seager, R., N. Harnik, Y. Kushnir, W. Robinson, and J. A. Miller(Velez), 2003: Mechanisms of hemispherically symmetric climate variability. Journal of Climate, 16, 2960-2978.

Sear, C. B., Kelly, P.M., Jones, P.D., and Goodess, C.M., 1987: Global surface-temperature responses to major volcanic eruptions. Nature 330, 365-367.

Simpkin, T. and L. Siebert, 1994: Volcanoes of the World (Smithsonian Institution, Geoscience Press, Tucson, Arizona, ed. 2).

Timmermann, A., J. Oberhuber, A. Bacher, M. Esch, M. Latif, and E. Roeckner, Increased El Nino frequency in a climate model forced by future greenhouse warming, Nature, 398, 694-697, 1999.

Trenberth, K.E., and T.J. Hoar, 1997: El Nino and climate change, Geophys. Res. Lett., 24, 3057-3060.

Verschuren, D., K.R. Laird, and B.F. Cumming, 2000: Rainfall and drought in equatorial east Africa during the past 1100 years, Nature, 403, 410-414.

Waple, A.M., M.E. Mann, and R.S. Bradley, 2002: Long-term patterns of solar irradiance forcing in model experiments and proxy based surface temperature reconstructions, Climate Dynamics, 18, 563-578.

Woodhouse, C.A. and J.T. Overpeck, 1998: 2000 years of drought variability in the central United States. American Meteorological Society Bulletin, 79, 2693-2714.

Zebiak, S.E. and M.A. Cane, 1987: A model El Niño/Southern Oscillation, Mon. Weather Rev. $115,2262-2278$. 
Figure 1 Ensemble-mean ZC Niño3 response to natural radiative forcing experiments over the period AD 1000-1999. a) Response to tropical volcanic radiative forcing (red-- anomaly in ${ }^{\circ} \mathrm{C}$ relative to AD 1000-1999 mean; scale provided on left axis) based on ensemble of 100 realizations. Radiative forcing (blue) is shown in $\mathrm{W} / \mathrm{m}^{2}$ (scale provided on right axis). b) Comparison of ensemble-mean responses to volcanic forcing (as in 'a') based on more modest ensembles of 20 (orange) and 5 (yellow) realizations. c) Response to solar radiative forcing (red-anomaly in ${ }^{\circ} \mathrm{C}$ relative to AD 1950-1980 reference period) based on ensemble of 100 realizations. Maroon curve represents 40 year smoothed response. Solar radiative forcing (blue) shown in $\mathrm{W} / \mathrm{m}^{2}$ (relative to AD 1000-1999 mean).

Figure 2 Superposed Epoch Analyses (SEA) for volcanic forcing experiments based on composites of (a) the 7 volcanic events exceeding $-2 \mathrm{~W} / \mathrm{m}^{2}$ over the AD 1649-1868 period and (b) the 7 volcanic forcing events exceeding $-4 \mathrm{~W} / \mathrm{m}^{2}$ over the AD 1000-1999 period. Anomalies represent departures relative to the pre-eruption mean. Vertical solid lines indicate the timing of occurrence of the eruption, values prior to the eruption are shown as a scatter plot, while post eruption values are shown as a continuous curve, to emphasize the structure in the post-eruption response. The horizontal dashed lines indicates $+/$ - two standard error (approximate 95\% confidence) intervals, while horizontal solid line indicates the composite pre-eruption mean. Year "0" defines the year during which the eruption occurs. Unlike Adams et al (2003) we have not normalized event magnitudes prior to compositing.

Figure 3 Comparison of the ensemble annual mean Niño3 response to the combined natural radiative forcing (volcanic+solar) over the interval AD 1000-1999. a) Response (red--anomaly in ${ }^{\circ} \mathrm{C}$ relative to AD 1000-1999 mean) to radiative forcing (blue) based on ensemble of 100 realizations. b) Comparison of model ensemble-mean Niño3 (gray--anomaly in ${ }^{\circ} \mathrm{C}$ relative to $\mathrm{AD}$ 
1950-1980 reference period; 40 year smoothed values shown by thick maroon curve) with reconstructions of ENSO behavior from Palmyra coral oxygen isotopes (blue--the annual means of the published monthly isotope data are shown). The coral data are scaled as described in the text, with warm-event (cold-event) conditions associated with negative (positive) isotopic departures. Thick dashed lines indicate averages of the scaled coral data for the three available time segments (blue) and the ensemble-mean averages from the model (red) for the corresponding time intervals. The associated inter-fourth quartile range for the model means (the interval within which the mean lies for $50 \%$ of the model realizations) is also shown. The ensemble mean is not at the center of this range, due to the skewed nature of the underlying distribution of the model Niño3 series. Also shown (green curve) is the 40 year smoothed model result based on the response to volcanic forcing only, with the mean shifted to match that of the coral segments. 

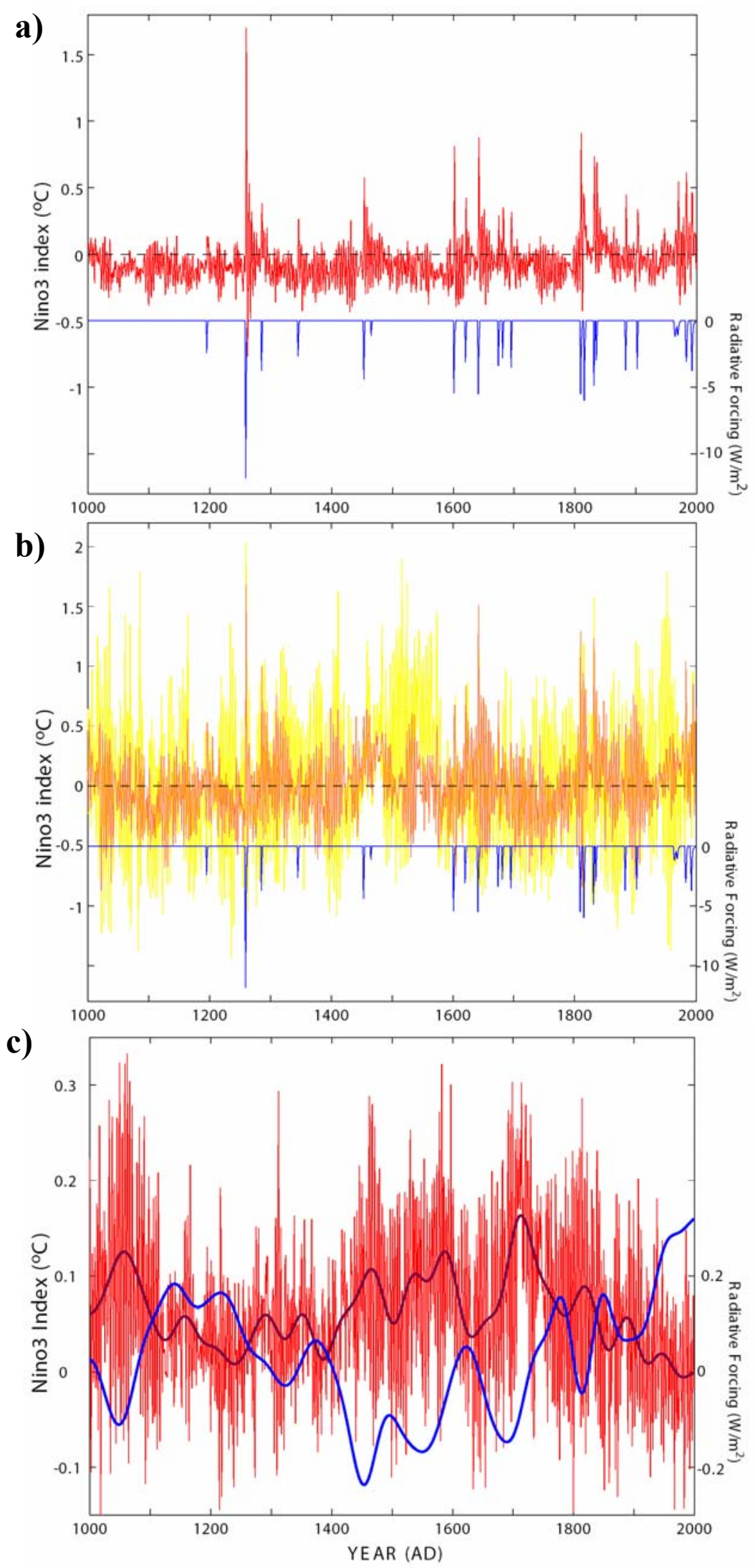

\section{FIGURE 1}




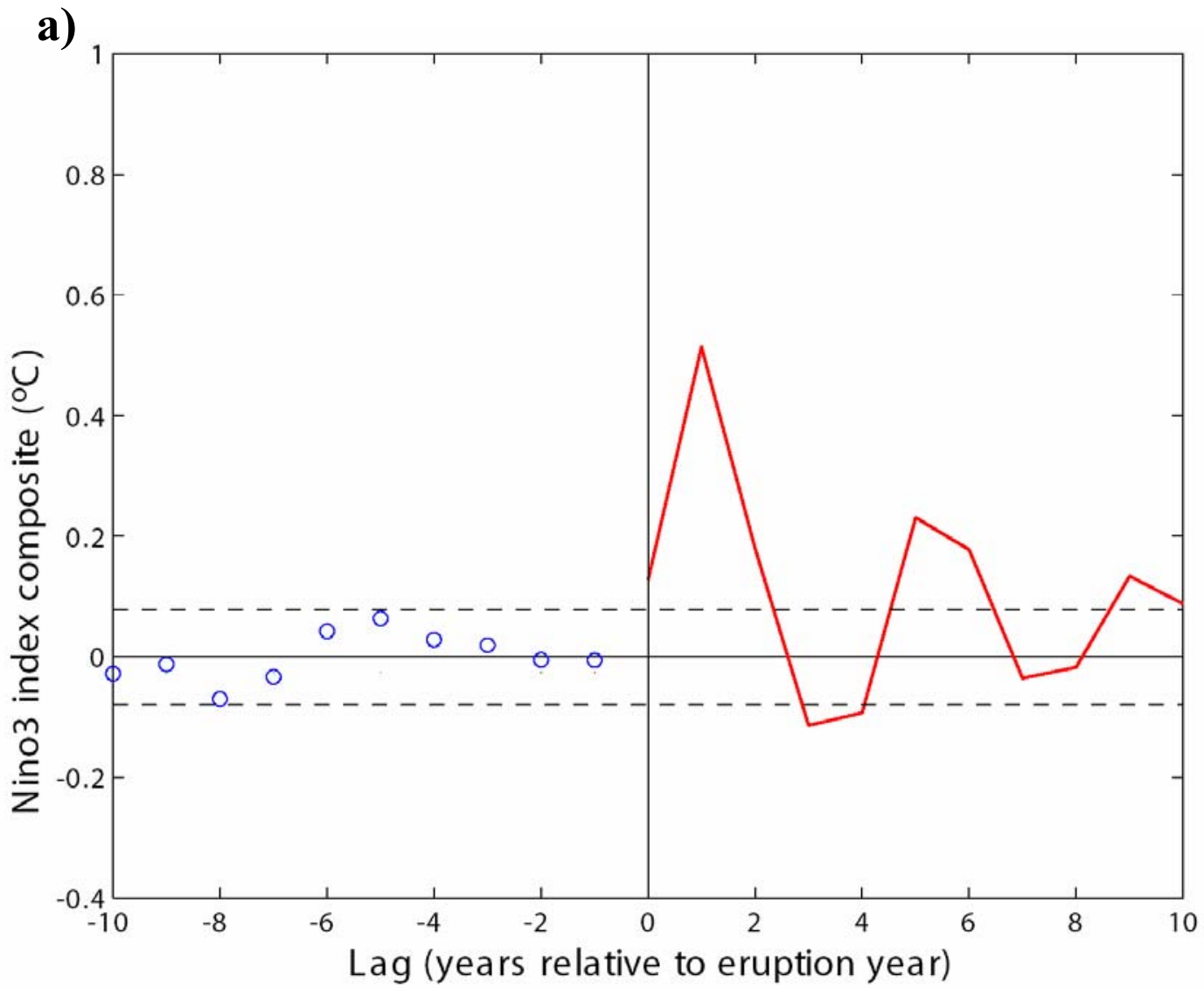

b)

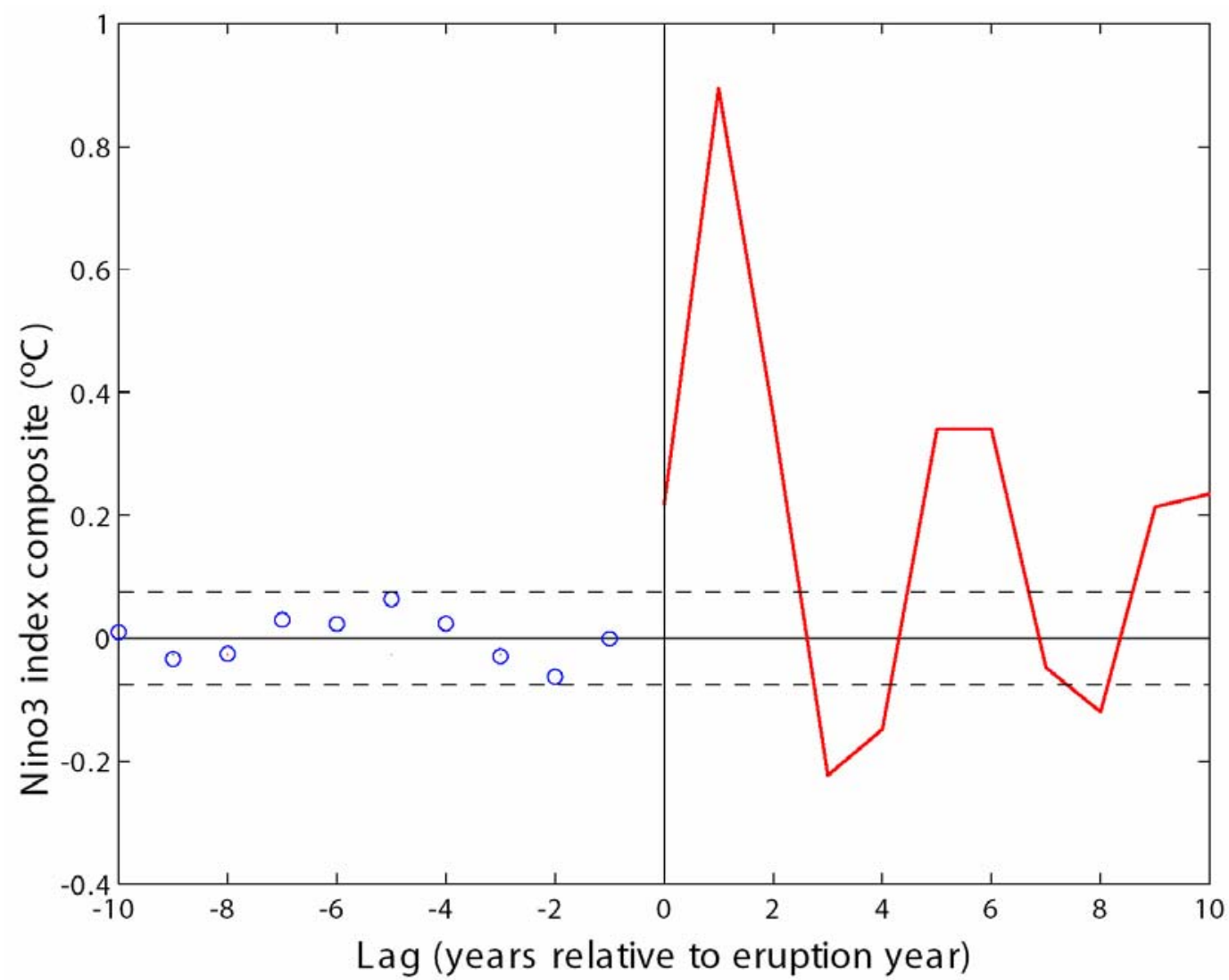

FIGURE 2 

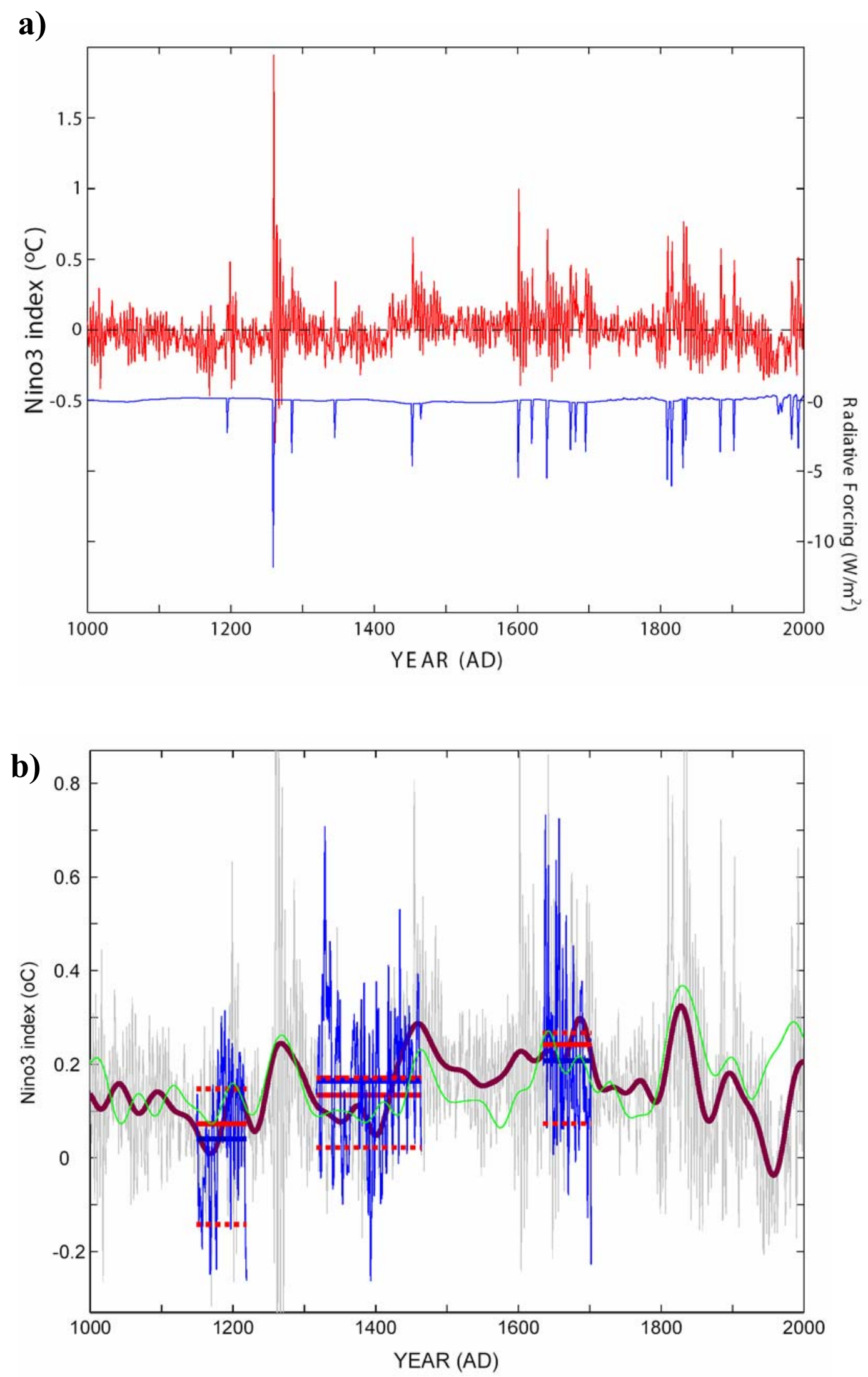

FIGURE 3 